\title{
Online tools to synthesize real-world evidence of comparative effectiveness research to enhance formulary decision making
}

\author{
Shuxian Chen, MA; Jennifer Graff, PharmD; Sophia Yun, PharmD; Brennan Beal, PharmD; Jamie T Ta, PharmD, MS; \\ Aasthaa Bansal, PhD; Joshua J Carlson, MPH, PhD; David L Veenstra, PharmD, PhD; Anirban Basu, PhD; \\ and Beth Devine, PhD, PharmD, MBA
}

\section{SUMMARY}

Results of randomized controlled trials (RCTs) provide valuable comparisons of 2 or more interventions to inform health care decision making; however, many more comparisons are required than available time and resources to conduct them. Moreover, RCTs have limited generalizability. Comparative effectiveness research (CER) using real-world evidence (RWE) can increase generalizability and is important for decision making, but use of nonrandomized designs makes their evaluation challenging. Several tools are available to assist.

In this study, we comparatively characterize 5 tools used to evaluate RWE studies in the context of making health care adoption decision making: (1) Good Research for Comparative Effectiveness (GRACE) Checklist, (2) IMI GetReal RWE Navigator (Navigator), (3) Center for Medical Technology Policy (CMTP) RWE Decoder, (4) CER Collaborative tool, and (5) Real World Evidence Assessments and Needs Guidance (REAdi) tool. We describe each and then compare their features along 8 domains: (1) objective/user/context, (2) development/ scope, (3) platform/presentation, (4) user design, (5) study-level internal/external validity of evidence, (6) summarizing body of evidence, (7) assisting in decision making, and (8) sharing results/making improvements.

Our summary suggests that the GRACE Checklist aids stakeholders in evaluation of the quality and applicability of individual CER studies. Navigator is a collection of educational resources to guide demonstration of effectiveness, a guidance tool to support development of medicines, and a directory of authoritative resources for RWE. The CMTP RWE Decoder aids in the assessment of relevance and rigor of RWE. The CER Collaborative tool aids in the assessment of credibility and relevance. The REAdi tool aids in refinement of the research question, study retrieval, quality assessment, grading the body of evidence, and prompts with questions to facilitate coverage decisions.

All tools specify a framework, were designed with stakeholder input, assess internal validity, are available online, and are easy to use. They vary in their complexity and comprehensiveness. The RWE Decoder, CER Collaborative tool, and REAdi tool synthesize evidence and were specifically designed to aid formulary decision making. This study adds clarity on what the tools provide so that the user can determine which best fits a given purpose.

\section{Author affiliations \\ Shuxian Chen, MA; Sophia Yun, PharmD; Brennan Beal, PharmD; Jamie T Ta, PharmD, MS; Aasthaa Bansal, PhD; Joshua J Carlson, MPH, PhD; David L Veenstra, PharmD, PhD; Anirban Basu, PhD; and Beth Devine, PhD, PharmD, MBA, The Comparative Health Outcomes, Policy and Economics (CHOICE) Institute, University of Washington School of Pharmacy, Seattle. Jennifer Graff, PharmD, National Pharmaceutical Council, Washington, DC.}

\section{AUTHOR CORRESPONDENCE: Beth Devine, 425.891.8074; bdevine@uw.edu}

J Manag Care Spec Pharm. 2021;27(1):95-104

Copyright $\odot 2021$, Academy of Managed Care Pharmacy. All rights reserved.
The limitations of traditional randomized controlled trials (RCTs) in informing health care decisions are well known, thus, the recent emphasis on comparative effectiveness research (CER). ${ }^{1-3}$ CER requires the use of real-world data (RWD), which is rapidly becoming more accessible, with a corresponding increase in demand for its synthesis into real-world evidence (RWE) to guide clinical practice and inform health technology adoption (HTA) decisions., ${ }^{4,5}$ Over time, managed care decision makers are likely to use more RWE, ${ }^{6}$ yet evaluating the quality and usefulness of RWE studies can be challenging. Tools are available to assist; however, they have not been compared. 
Early efforts to develop a framework to assist health care decision makers in using RWD were led by the International Society for Health Economics and Outcomes Research (ISPOR). ${ }^{7}$ In 2017, the ISPOR-International Society for Pharmacoepidemiology (ISPE) Special Task Force on RWE in Health Care Decision Making established good procedural practice intended to enhance confidence by decision makers in RWE derived from RWD. ${ }^{8}$ In 2019, the RWE Transparency Initiative, a partnership among ISPOR, ISPE, the Duke-Margolis Center for Health Policy, and the National Pharmaceutical Council (NPC) released a draft white paper recommending widespread use of registries to improve transparency of RWE studies. ${ }^{9}$ The AMCP Format for Formulary Submissions, Version 4.1 has evolved to include RWE as part of clinical evidence. ${ }^{6}$ The Institute for Clinical and Economic Review (ICER) has described the opportunities and challenges of using RWE for coverage decisions and developed a framework to guide optimal development and use of RWE for this purpose. ${ }^{10,11}$ Governmental and quasi-governmental agencies have been leading similar efforts. ${ }^{12-18}$

In the context of CER, HTA decision makers are seldom positioned to conduct RWE studies or to undertake comprehensive systematic reviews to inform timely decision making. Existing barriers have slowed the rate at which RWE is used in decision making. ${ }^{19-21}$ This situation has led to a rise in the development of a number of tools to guide HTA decision making. Yet, in our own HTA work, we find that colleagues are still seeking clarity about how to evaluate RWE. This uncertainty led to creation of the Real World Evidence Assessments and Needs Guidance (REAdi) tool (by the University of Washington's Comparative Health Outcomes, Policy and Economics [CHOICE] Institute) and, eventually, to a comparison of the features of all 5 tools highlighted in this study.

\section{Program Description}

\section{DESCRIPTION OF CURRENT TOOLS}

In this report, we describe the 5 best practice tools identified by experts in CER and RWE: the Good Research for Comparative Effectiveness (GRACE) Checklist, the Innovative Medicines Initiative (IMI) GetReal RWE Navigator, the Center for Medical Technology and Policy (CMTP) RWE Decoder, the CER Collaborative tool, and the REAdi tool (Table 1). ${ }^{22-35}$

1. GRACE Checklist. ${ }^{22-25}$ The GRACE Checklist was derived from a set of principles that define the elements of good practice for the design, conduct, analysis, and reporting of observational CER studies. The original GRACE principles were developed by Outcome Sciences (now part of IQVIA) with funding from the NPC and have been endorsed by ISPE. The principles served as the foundation for the 11-item GRACE Checklist that aids stakeholders in the evaluation of the quality and applicability of CER studies. The validated checklist was developed from a review of published literature and was tested globally by volunteers.

2. IMI GetReal RWE Navigator. ${ }^{26,27}$ Launched in 2018, the GetReal Initiative is a public-private partnership of pharmaceutical companies, academia, HTA agencies, and regulators across the European Union. The goal is to increase the quality of RWE generation in medicines development and regulatory/HTA processes, optimizing and ensuring adoption and sustainability of the tools earlier developed under the "GetReal" Consortium. The online RWE Navigator includes educational resources to guide demonstration of effectiveness, a guidance tool to support development of medicines, and a directory of and links to authoritative resources for evaluation of RWE, including quality and credibility. Navigator maps the landscape of RWE to help users "navigate" to what they need to prioritize and make decisions.

3. CMTP RWE Decoder. ${ }^{28-30}$ The online CMTP RWE Decoder was developed through a multistakeholder initiative for the purpose of making available an easy-to-use tool to help decision makers confidently and consistently assess RWE for their decision making needs. The tool is an Excel spreadsheet that facilitates user assessment of the relevance and rigor of existing evidence from RCTs and RWE. Finalized in 2017, RWE Decoder is composed of 3 modules. In Module 1, the user articulates the question of interest, framing the question in the PICOTS (population, intervention, comparators, outcomes, timing, setting) format. Module 2a provides the framework for assessing the relevance of each identified study. Module $2 \mathrm{~b}$ prompts for assessment of the rigor of each individual study, including the quality of the evidence, potential for bias, precision, and data integrity. Module $2 \mathrm{c}$ calls for the magnitude and direction of effect. In Module 3, an integrated summary of each of these assessments is presented in graphical format. RWE Decoder is available in the public domain.

4. CER Collaborative Tool. ${ }^{31-34}$ Developed by the CER Collaborative, a multistakeholder initiative of NPC, AMCP, and ISPOR, the CER Collaborative tool helps users synthesize RWE and assess its credibility and relevance of evidence. The goal is to provide greater uniformity and transparency in the evaluation of RWE to inform HTA decisions. The CER Collaborative tool facilitates the critical appraisal of 4 types of studies (prospective and retrospective observational 
TABLE 1 Comparison of Tools to Assess Real-World Evidence

\begin{tabular}{|c|c|c|c|c|c|}
\hline & $\begin{array}{c}\text { GRACE } \\
\text { Checklist }^{22-25} \\
\end{array}$ & $\begin{array}{l}\text { IMI GetReal RWE } \\
\text { Navigator } 26,27\end{array}$ & $\begin{array}{l}\text { CMTP RWE } \\
\text { Decoder 28-30 }\end{array}$ & $\begin{array}{c}\text { CER } \\
\text { Collaborative } \\
\text { 31-34 }\end{array}$ & $\begin{array}{l}\text { UW REAdi } \\
\text { Tool }^{35}\end{array}$ \\
\hline \multicolumn{6}{|c|}{ Domain 1: Objective, targeted user, and context of use } \\
\hline Objective & $\begin{array}{c}\text { Review the quality of } \\
\text { observational studies } \\
\text { to support decision } \\
\text { making, and a set of } \\
\text { questions to guide } \\
\text { the design, conduct, } \\
\text { analysis, and reporting } \\
\text { of observational CER } \\
\text { studies }\end{array}$ & $\begin{array}{c}\text { Increase awareness } \\
\text { about the use } \\
\text { of RWE and } \\
\text { to understand } \\
\text { concepts related to } \\
\text { RWE }\end{array}$ & $\begin{array}{c}\text { Aid health care } \\
\text { decision makers in } \\
\text { use RWE when making } \\
\text { coverage decisions and } \\
\text { care choices }\end{array}$ & $\begin{array}{l}\text { Aid decision makers } \\
\text { to synthesize } \\
\text { evidence from } \\
\text { multiple studies in } \\
\text { a consistent and } \\
\text { transparent manner } \\
\text { to guide coverage } \\
\text { and formulary } \\
\text { decisions }\end{array}$ & $\begin{array}{l}\text { Aid decision makers } \\
\text { to synthesize } \\
\text { evidence from } \\
\text { multiple studies in } \\
\text { a consistent and } \\
\text { transparent manner } \\
\text { to guide coverage } \\
\text { and formulary } \\
\text { decisions }\end{array}$ \\
\hline Target user & $\begin{array}{c}\text { Health care } \\
\text { decision makers }\end{array}$ & $\begin{array}{l}\text { Wide variety of } \\
\text { users including } \\
\text { pharmaceutical } \\
\text { companies and } \\
\text { patients }\end{array}$ & $\begin{array}{c}\text { Health care } \\
\text { decision makers }\end{array}$ & $\begin{array}{c}\text { Health care } \\
\text { decision makers }\end{array}$ & $\begin{array}{c}\text { Health care } \\
\text { decision makers }\end{array}$ \\
\hline $\begin{array}{l}\text { Level of tool } \\
\text { complexity (see } \\
\text { text and URLs to } \\
\text { each tool) }\end{array}$ & Basic & Basic & Novice & Intermediate & Advanced \\
\hline Context of use & No & No & Yes & Yes & Yes \\
\hline \multicolumn{6}{|c|}{ Domain 2: Development and scope } \\
\hline RWE only & $\begin{array}{l}\text { Yes, not intended for } \\
\text { RCTs }\end{array}$ & $\begin{array}{c}\text { Yes, not intended for } \\
\text { RCTs }\end{array}$ & $\begin{array}{l}\text { No, allows the review } \\
\text { of RCT and non-RCT } \\
\text { studies }\end{array}$ & $\begin{array}{l}\text { No, allows the } \\
\text { review of RCT and } \\
\text { non-RCT studies }\end{array}$ & $\begin{array}{c}\text { Yes, not intended for } \\
\text { RCTs }\end{array}$ \\
\hline $\begin{array}{l}\text { Stakeholders } \\
\text { involved in } \\
\text { development }\end{array}$ & $\begin{array}{l}\text { Developed through } \\
\text { literature review } \\
\text { and consultation } \\
\text { with experts from } \\
\text { professional societies, } \\
\text { payer groups, the } \\
\text { private sector, } \\
\text { and academia. } \\
\text { Collaborators includes } \\
\text { the ISPE, NPC }\end{array}$ & $\begin{array}{l}\text { Developed through } \\
\text { an EU public- } \\
\text { private consortium } \\
\text { comprised of } \\
\text { pharmaceutical } \\
\text { companies, } \\
\text { academia, HTA } \\
\text { agencies and } \\
\text { regulators, patient } \\
\text { organizations and } \\
\text { small and medium- } \\
\text { sized enterprises }\end{array}$ & $\begin{array}{l}\text { Developed by the Green } \\
\text { Park Collaborative, } \\
\text { which works to } \\
\text { improve clinical } \\
\text { research by cultivating } \\
\text { collaborations between } \\
\text { drug and device } \\
\text { developers, private and } \\
\text { public payers, clinicians, } \\
\text { researchers, regulators, } \\
\text { and the patients that } \\
\text { they all serve }\end{array}$ & $\begin{array}{l}\text { Developed through } \\
\text { a collaboration } \\
\text { among AMCP, } \\
\text { ISPOR, NPC }\end{array}$ & $\begin{array}{l}\text { Developed through } \\
\text { a collaboration } \\
\text { between } 1 \text { academic } \\
\text { center with input } \\
\text { from health } \\
\text { sciences librarians } \\
\text { and a local payer; } \\
\text { beta-tested at the } \\
2018 \text { AMCP Nexus } \\
\text { meeting, Orlando, FL }\end{array}$ \\
\hline $\begin{array}{l}\text { Developed } \\
\text { using a specified } \\
\text { framework; } \\
\text { contains a tool }\end{array}$ & Yes/yes & Yes/yes & Yes/yes & Yes/yes & Yes/yes \\
\hline Region of focus & $\begin{array}{l}\text { United States } \\
\text { and Europe }\end{array}$ & Europe & United States & $\begin{array}{l}\text { United States } \\
\text { and Europe }\end{array}$ & United States \\
\hline \multicolumn{6}{|c|}{ Domain 3: Platform and presentation } \\
\hline $\begin{array}{l}\text { Platform and } \\
\text { presentation }\end{array}$ & $\begin{array}{l}\text { 11-item checklist; } \\
\text { pdf available online }\end{array}$ & Online resources & Spreadsheet online & $\begin{array}{c}\text { Series of } \\
\text { questionnaires } \\
\text { accessed through } \\
\text { online portal; } \\
\text { downloadable } \\
\text { summary report or } \\
\text { monograph }\end{array}$ & $\begin{array}{c}\text { R-Shiny app; } \\
\text { downloadable } \\
\text { summary report or } \\
\text { monograph }\end{array}$ \\
\hline Cost & 0 & 0 & 0 & 0 & 0 \\
\hline Publicly available & Yes & Yes & Yes & Yes & Yes \\
\hline
\end{tabular}




\section{TABLE 1 Comparison of Tools to Assess Real-World Evidence (continued)}

\begin{tabular}{|c|c|c|c|c|c|}
\hline & $\begin{array}{c}\text { GRACE } \\
\text { Checklist }^{22-25}\end{array}$ & $\begin{array}{l}\text { IMI GetReal RWE } \\
\text { Navigator }\end{array}$ & $\begin{array}{l}\text { CMTP RWE } \\
\text { Decoder }^{28-30}\end{array}$ & $\begin{array}{c}\text { CER } \\
\text { Collaborative }^{31-34}\end{array}$ & $\begin{array}{l}\text { UW REAdi } \\
\text { Tool }^{35}\end{array}$ \\
\hline \multicolumn{6}{|c|}{ Domain 4: User design comparison } \\
\hline $\begin{array}{l}\text { Provides } \\
\text { definitions } \\
\text { of terms }\end{array}$ & Yes & Yes & Yes & Yes & Yes \\
\hline $\begin{array}{l}\text { Types of } \\
\text { interventions } \\
\text { incorporated in } \\
\text { the tool }\end{array}$ & $\begin{array}{l}\text { Not limited to } \\
\text { pharmaceuticals }\end{array}$ & $\begin{array}{c}\text { Focus on } \\
\text { pharmaceuticals }\end{array}$ & $\begin{array}{l}\text { Not limited to } \\
\text { pharmaceuticals }\end{array}$ & $\begin{array}{l}\text { Not limited to } \\
\text { pharmaceuticals }\end{array}$ & $\begin{array}{l}\text { Not limited to } \\
\text { pharmaceuticals }\end{array}$ \\
\hline $\begin{array}{l}\text { Applied PICOTS } \\
\text { to specify } \\
\text { questions }\end{array}$ & $\begin{array}{l}\text { Not named as } \\
\text { such but includes } \\
\text { diseases/conditions, } \\
\text { comparators, treatment } \\
\text { regimens, and patient } \\
\text { characteristics }\end{array}$ & $\begin{array}{l}\text { Included PICOTS, } \\
\text { allows user to select } \\
\text { one at a time }\end{array}$ & $\begin{array}{c}\text { Yes } \\
\text { PICOTS considered }\end{array}$ & $\begin{array}{c}\text { Yes } \\
\text { PICOTS considered }\end{array}$ & $\begin{array}{c}\text { Yes } \\
\text { PICOTS considered }\end{array}$ \\
\hline $\begin{array}{l}\text { Allows } \\
\text { specification } \\
\text { of primary } \\
\text { and secondary } \\
\text { outcomes }\end{array}$ & Yes & No & Yes & Yes & Yes \\
\hline $\begin{array}{l}\text { Allows users to } \\
\text { design and tailor } \\
\text { research questions } \\
\text { of interest to guide } \\
\text { literature search }\end{array}$ & No & No & No & No & $\begin{array}{c}\text { Yes, PICOTS } \\
\text { developed first, } \\
\text { followed by a list } \\
\text { of detailed areas } \\
\text { of interest to help } \\
\text { users tailor their } \\
\text { questions }\end{array}$ \\
\hline $\begin{array}{l}\text { Provides a } \\
\text { comprehensive } \\
\text { list of study } \\
\text { designs }\end{array}$ & No & Yes & No & $\begin{array}{l}\text { No (focused on } \\
\text { prospective and } \\
\text { retrospective } \\
\text { observational } \\
\text { studies, (NMAs, } \\
\text { CEAs) }\end{array}$ & Yes \\
\hline $\begin{array}{l}\text { Guides users to } \\
\text { appropriate study } \\
\text { designs }\end{array}$ & No & No & No & No & Yes \\
\hline $\begin{array}{l}\text { Provides } \\
\text { customized } \\
\text { PubMed search } \\
\text { based on defined } \\
\text { questions of } \\
\text { interest }\end{array}$ & No & No & No & No & Yes \\
\hline $\begin{array}{l}\text { Level of user } \\
\text { interactivity (low, } \\
\text { moderate, good) }\end{array}$ & Low & Low & Good & Good & Good \\
\hline \multicolumn{6}{|c|}{ Domain 5: Assess internal and external validity from evidence } \\
\hline $\begin{array}{l}\text { Provides } \\
\text { systematic } \\
\text { method to assess } \\
\text { internal validity } \\
\text { (e.g., specific risk } \\
\text { of bias/quality } \\
\text { evaluation) }\end{array}$ & $\begin{array}{c}\text { Yes, lists various } \\
\text { types of biases } \\
\text { including selection, } \\
\text { misclassification, } \\
\text { detection, performance } \\
\text { bias, and attrition } \\
\text { biases }\end{array}$ & $\begin{array}{l}\text { Yes, listed different } \\
\text { checklists for } \\
\text { quality assessment }\end{array}$ & $\begin{array}{l}\text { Assesses data integrity, } \\
\text { potential for bias, } \\
\text { precision; } 1 \text { bias tool for } \\
\text { RCTs, } 1 \text { for non-RCTs }\end{array}$ & $\begin{array}{c}\text { Yes, assesses } \\
\text { credibility } \\
\text { using checklists } \\
\text { corresponding } \\
\text { to design, data, } \\
\text { analysis, reporting, } \\
\text { and interpretation } \\
\text { domains }\end{array}$ & $\begin{array}{c}\text { Yes, uses a wide } \\
\text { collection of } \\
\text { publicly available } \\
\text { tools } \\
\text { (39-46 }\end{array}$ \\
\hline
\end{tabular}




\section{TABLE 1 Comparison of Tools to Assess Real-World Evidence (continued)}

\begin{tabular}{|c|c|c|c|c|c|}
\hline & $\begin{array}{c}\text { GRACE } \\
\text { Checklist }^{22-25} \\
\end{array}$ & $\begin{array}{l}\text { IMI GetReal RWE } \\
\text { Navigator }\end{array}$ & $\begin{array}{l}\text { CMTP RWE } \\
\text { Decoder 28-30 }\end{array}$ & $\begin{array}{c}\text { CER } \\
\text { Collaborative } \\
\text { 31-34 }\end{array}$ & $\begin{array}{l}\text { UW REAdi } \\
\text { Tool }^{35}\end{array}$ \\
\hline \multicolumn{6}{|c|}{ Domain 5: Assess internal and external validity from evidence } \\
\hline $\begin{array}{l}\text { Provides } \\
\text { systematic method } \\
\text { to assess external } \\
\text { validity }\end{array}$ & No & Yes & Yes, assesses relevance & $\begin{array}{l}\text { Yes, assesses } \\
\text { relevance }\end{array}$ & $\begin{array}{l}\text { Yes, assesses } \\
\text { relevance }\end{array}$ \\
\hline \multicolumn{6}{|c|}{ Domain 6: Features to summarize the body of evidence } \\
\hline $\begin{array}{l}\text { Methods for } \\
\text { summarizing the } \\
\text { body of RWE }\end{array}$ & $\begin{array}{l}\text { No (used for individual } \\
\text { studies but not the body } \\
\text { of evidence) }\end{array}$ & $\begin{array}{l}\text { Mentions GRADE } 47 \\
\text { criteria but does not } \\
\text { build it in }\end{array}$ & $\begin{array}{l}\text { Uses } 3 \text { dimensions } \\
\text { (rigorous, relevance, } \\
\text { effect size); provides } \\
\text { 3-dimensional graphic } \\
\text { representation of } \\
\text { summary }\end{array}$ & $\begin{array}{l}\text { Two dimensions } \\
\text { (magnitude of } \\
\text { benefit and } \\
\text { certainty of benefit); } \\
\text { provides a graphic } \\
\text { representation } \\
\text { on an illustrative } \\
\text { evidence rating } \\
\text { matrix }\end{array}$ & $\begin{array}{l}\text { Uses GRADE }{ }^{47} \\
\text { criteria to } \\
\text { summarize the body } \\
\text { of evidence }\end{array}$ \\
\hline \multicolumn{6}{|c|}{ Domain 7: Features to assist decision making } \\
\hline $\begin{array}{l}\text { Provides a } \\
\text { structured } \\
\text { framework for } \\
\text { decision making }\end{array}$ & Yes & Yes & Yes & Yes & Yes \\
\hline $\begin{array}{l}\text { Provides } \\
\text { recommendations } \\
\text { for decision } \\
\text { making }\end{array}$ & No & No & No & No & Yes \\
\hline $\begin{array}{l}\text { Provides } \\
\text { documentation } \\
\text { of tool usage }\end{array}$ & Yes, pdf & No & Yes, Excel & $\begin{array}{l}\text { Yes, Excel, Word, } \\
\text { and pdf }\end{array}$ & $\begin{array}{l}\text { Yes, print screen } \\
\text { and save multiple } \\
\text { projects }\end{array}$ \\
\hline \multicolumn{6}{|c|}{ Domain 8: Ability to share results with others and collect data to facilitate iterative improvements } \\
\hline $\begin{array}{l}\text { Capability of tool } \\
\text { to share results }\end{array}$ & Yes & Yes & Yes & Yes & Yes \\
\hline $\begin{array}{l}\text { Capability of } \\
\text { tool designer to } \\
\text { log, collect, and } \\
\text { analyze user } \\
\text { inputs to facilitate } \\
\text { tool improvements }\end{array}$ & No & No & No & No & Yes \\
\hline
\end{tabular}

CEA = cost-effectiveness analysis; CER = comparative effectiveness research; CMTP=Center for Medical Technology Policy; GRACE = Good Research for Comparative Effectiveness; GRADE = Grading of Recommendations, Assessment, Development and Evaluations; HTA = health technology adoption; IMI =Innovative Medicines Initiative; ISPE = International Society for Pharmacoepidemiology; NMA = network meta-analysis; NPC= National Pharmaceutical Council; PICOTS=population, intervention, comparator, outcomes, timing, setting; RCT = randomized controlled trial; REAdi = Real-World Evidence Assessments and Needs Guidance; RWE = realworld evidence.

studies, modeling studies, and indirect treatment comparisons) and is composed of 2 parts. Part 1 involves critical appraisal of individual studies along 2 dimensions: (1) relevance, using the PICOTS framework, and (2) credibility, by critiquing study design, data sources, analyses, reporting, interpretation, and conflicts of interest. In Part 2, evidence from multiple studies of varying designs is synthesized and assessed for reliability along 2 dimensions: (1) magnitude of comparative net health benefit and (2) evidence certainty. A joint rating is generated and presented graphically using the Evidence Rating Matrix from ICER with an available export function for formulary monographs. ${ }^{36,37}$ The CER Collaborative tool is online and interactive. Training modules and video tutorials are available. A 19-hour CER certificate program accredited by the American Council on Pharmaceutical Education was offered for a fee. ${ }^{38}$ 


\section{TABLE 2 REAdi Tool ${ }^{35}$ : Evidence-Based Recommendations in Phase 3}

\begin{tabular}{|c|c|}
\hline RWE Considerations & Recommendations \\
\hline $\begin{array}{l}\text { - The benefit-risk trade-off } \\
\text { - Employee productivity } \\
\text { - Important values and preferences of } \\
\text { stakeholders (patients/employers) } \\
\text { - Whether adoption is feasible } \\
\text { - Opportunity cost of reviewing RWE } \\
\text { - Affordability of the intervention } \\
\text { - Patient burden } \\
\text { - Acceptability of the intervention to providers } \\
\text { and patients } \\
\text { - Equitably delivery of this intervention across } \\
\text { the population. }\end{array}$ & $\begin{array}{l}\text { - No coverage } \\
\text { - Performance-based risk-sharing } \\
\text { arrangements (PBRSA) } \\
\text { - Coverage with guidelines } \\
\text { - Coverage with policy } \\
\text { - Coverage with prior authorization criteria } \\
\text { (e.g., step therapy) } \\
\text { - Benefit or product beneficial context rules } \\
\text { (in the actual beneficial context, e.g., we are } \\
\text { not going to pay for weight loss) }\end{array}$ \\
\hline
\end{tabular}

REAdi $=$ Real-World Evidence Assessments and Needs Guidance; $R W E=$ real-world evidence

5. REAdi Tool. ${ }^{35}$ The REAdi tool was developed by investigators at the University of Washington's Comparative Health Outcomes, Policy and Economics (CHOICE) Institute. Intended to provide guidance on the use of RWE for HTA decision making for drug and diagnostic interventions, the REAdi framework is comprehensive in leading the user through the decisionmaking process in 5 phases. In Phase 1 , the user defines the research question in the PICOTS format. Once defined, the tool automatically synthesizes terms to create a PubMed search strategy; citations of relevant studies are returned for review. In Phase 2, the user reviews and quality-rates the RWE on a per-study basis, having been guided to an embedded qualityrating tool specific to each included study design..39-46 Once completed, in Phase 3, the user is prompted to rate the strength of the body of evidence using GRADEPro (Grading of Recommendations, Assessment, Development and Evaluations).47 In Phase 4, the user assesses the applicability and sufficiency of the evidence for the intended purpose. In Phase 5, questions are posed to facilitate coverage decisions relevant to immediate payer decision need (Table 2). Constructed using an R-Shiny app ${ }^{48}$ the publicly available, online REAdi tool uses drop-down menus, branching logic, and piping, such that questions posed in subsequent tasks are based on previous answers. A graphical summary is presented. The tool also harbors the functionality to print screen and save literature reviews, allowing one to work on multiple projects simultaneously.

\section{Observations}

\section{COMPARISON OF THE 5 TOOLS}

In October 2018, CHOICE investigators were joined by a collaborator from NPC (Graff) at the AMCP Nexus meeting (Orlando, FL) in leading an invited workshop to compare, contrast, and offer an opportunity to use 3 of these tools, using a case study from the literature. ${ }^{49}$ In this article, we describe and compare those 3 tools and add comparisons of the GRACE Checklist and the IMI Navigator. In evaluating each tool, we have identified 27 features. For comparison, we informally organized these into 8 domains
(Table 1). Domains 1 through 4 provide a description of the features of each tool. Domains 5 through 7 describe the flow of RWE decision making. Domain 8 applies after completion of use and describes the ability of each tool to collect data to facilitate iterative improvements.

Domain 1: Objective, Targeted User, and Context of Use. The objectives of the GRACE Checklist and IMI Navigator are each unique-the GRACE Checklist provides a simple tool to review study quality and guide aspects of CER studies, while the Navigator aims to increase awareness and understanding of RWE and has multiple uses. The RWE Decoder, CER Collaborative tool, and REAdi tool are each intended to guide formulary decision making. While the target users of the Navigator are a broad group of stakeholders, the target users of the other 4 tools are health care decision makers. The GRACE Checklist and Navigator are designed at a basic level of complexity, whereas the RWE Decoder, CER Collaborative tool, and REAdi tool are increasingly complex, while still being relatively easy to use. Aligned with the objective, the context of use of the RWE Decoder, CER Collaborative tool, and REAdi tool are specified; this is not the case with the GRACE Checklist and Navigator.

Domain 2: Development and Scope. Three of the five tools are intended for use with RWE only, while the RWE Decoder and CER Collaborative tool allow for consideration of RCTs. Stakeholders were involved in development of all 5 tools, and a framework for decision making is specified for each. The RWE Decoder and REAdi tool have a U.S. focus, whereas the Navigator was developed for use in Europe, and the GRACE Checklist and CER Collaborative tool are intended for international use. 
Domain 3: Platform and Presentation. All tools are available online, in PDF format (GRACE Checklist), webpages (Navigator and the CER Collaborative tool), Microsoft Excel (RWE Decoder), or R Shiny (REAdi). All are publicly available at no cost.

Domain 4: User Design Comparison. All tools provide definitions of terms. Navigator is focused solely on pharmaceutical interventions; the others are not limited to intervention category. All 5 tools have adopted at least some elements of the PICOTS framework. All but Navigator allow specification of primary and secondary outcomes simultaneously. Neither the GRACE Checklist nor the RWE Decoder provide a list of study designs to which each tool can be applied. The Navigator and REAdi tool accommodate many study designs, while the CER Collaborative focuses on cohort studies, cost-effectiveness analyses, and (network) meta-analyses. The REAdi tool explicitly allows users to design and tailor research questions, guiding them to appropriate study designs, and assists users in constructing key words and search strategies that result in automatic execution of a PubMed search. As a checklist and collection of online resources, neither the GRACE Checklist nor Navigator are digitally interactive, while RWE Decoder, the CER Collaborative tool, and the REAdi tool are.

Domain 5: Assess Internal and External Validity of Evidence. All tools provide a systematic method to assess internal validity (quality/bias); Navigator provides links to quality rating tools, while the REAdi tool embeds most of these. RWE Decoder provides 1 tool each for assessing the rigor of RCTs and non-RCTs, using the quality of the research questions, potential for bias, precision, and data integrity. The CER Collaborative tool assesses credibility using checklists corresponding to design, data, analysis, reporting, and interpretation. RWE Decoder, IMI Navigator, the CER Collaborative tool, and the REAdi tool assess relevance, that is, external validity, while the GRACE Checklist does not.

Domain 6: Features to Summarize the Body of Evidence. The tools vary in their methods for summarizing the body of RWE. The GRACE Checklist is applicable only to individual studies. Navigator mentions the GRADE criteria, but GRADE is not a built-in feature. RWE Decoder uses a 3-dimensional graphic to summarize relevance, rigor, and effect size. The CER Collaborative tool has adopted ICER's Evidence Rating Matrix that illustrates magnitude and certainty in 2 dimensions, which follows the GRADE methods. The REAdi tool has embedded the GRADEPro criteria.

Domain 7: Features to Assist Decision Making. All 5 tools provide a structured framework for decision making, while the REAdi tool also provides recommendations for decision making. All except the Navigator provide documentation of tool usage, with the GRACE Checklist using PDF format and RWE Decoder and the CER Collaborative tool using Excel; the CER Collaborative tool also uses Word. The REAdi tool prints screen and saves projects.

Domain 8: Ability to Share Results with Others and Collect Data to Facilitate Iterative Improvements. Each tool allows users to save their ratings and share with other users. Only the REAdi tool is designed to log, collect, and analyze user inputs to facilitate iterative improvements in features.

\section{Implications}

We reviewed 5 online tools to synthesize RWE of CER, which vary in their objectives, complexity, and context for use. The simplest to use, the GRACE Checklist, provides a simple quality rating, while the Navigator provides education, guidance, and resources. The 3 remaining tools-RWE Decoder, the CER Collaborative tool, and the REAdi tool are similar to each other in that they integrate quality ratings, education, and guidance resources. They are therefore more complex and are intended to evaluate a body of RWE to enhance formulary decision making. The RWE Decoder and CER Collaborative tool are useful for evaluating already identified evidence, while the REAdi tool spans a broader set of decision-making tasks by beginning upstream in explicitly assisting the user in specifying the research questions and finishing downstream by offering recommendations for formulary decision making. With their varying features, breadth of tasks, and levels of complexity, the RWE Decoder, CER Collaborative tool, and REAdi tool synthesize evidence and were specifically designed to aid formulary decision making.

\section{Conclusions}

This study characterizes 5 potentially useful tools for HTA decision making using RWE. Because use of RWE is low, research that explores awareness, usefulness, and barriers to use of these tools may result in their improvement, uptake in their use, and ultimately increased use of RWE for decision making. ${ }^{19-21}$ Future research could also include a more in-depth comparison of these tools in the context of case studies to determine which features are of greatest value to decision makers. Best practices for tool use could then be developed and existing tools integrated. A discussion could then ensue about strategies to sustain the new tool. In the meantime, this study adds clarity on what the tools provide so that the user can determine which best fits a given purpose. 


\section{DISCLOSURES}

This work was supported by the Health Tech Fund, which was provided to the University of Washington School of Pharmacy by its Corporate Advisory Board. This consortium of pharmaceutical and biotech companies supports the research program of the University of Washington School of Pharmacy across the competitive space. The sponsors seeded the idea for the project and contributed to study design and improvement. The authors had full control of all content development, manuscript drafting, and submission for publication. The REAdi tool was developed by the authors.

Chen, Bansal, Barthold, Carlson, Veenstra, Basu, Devine, Yun, Ta, and Beal were supported by a training grant from the University of WashingtonAllergan Fellowship, unrelated to this work. Basu reports personal fees from Salutis Consulting, unrelated to this work. Graff is an employee of the National Pharmaceutical Council, which was a partner in the development of the CER Collaborative and funding partner for the CMTP RWE Decoder and the GRACE Checklist.

A previous version of this work was presented as an invited workshop at AMCP Nexus 2018; October 22-25, 2018; Orlando, FL.

\section{ACKNOWLEDGMENTS}

The authors thank the following individuals who participated in development of the REAdi tool: D. Louden and J. Rich for their assistance in refining REAdi's PubMed search strategy; D. Barthold and several colleagues from a health plan in the Pacific Northwest for contributing to content development; T. Hopkins, A. Kim, and E. Neuberger for beta testing; and the attendees at the invited workshop delivered at AMCP Nexus 2018 in Orlando, FL, for providing feedback.

\section{REFERENCES}

1. American Recovery and Reinvestment Act of 2009, HR 1, 111th Cong, 1st Sess (2009). Accessed December 3, 2020. https://www.govinfo.gov/content/pkg/ BILLS-111hrlenr/pdf/BILLS-111hrlenr.pdf

2. Conway PH, Clancy C. Comparativeeffectiveness research-implications of the Federal Coordinating Council's report. N Engl J Med. 2009;361(4):328-30.
3. Sox HC, Greenfield S. Comparative effectiveness research: a report from the Institute of Medicine. Ann Intern Med. 2009;151(3):203-W44

4. Corrigan-Curay J, Sacks L, Woodcock J. Real-world evidence and real-world data for evaluating drug safety and effectiveness. JAMA. 2018;320(9):867-68.

5. U.S. Food and Drug Administration. Real-world evidence. Retrieved May 9 , 2019. Updated November 30, 2020. Accessed December 3, 2020. https:// www.fda.gov/science-research/ science-and-research-special-topics/ real-world-evidence

6. AMCP. The AMCP Format for Formulary Submissions. Version 4.1. December 2019. Accessed December 3, 2020. https:// www.amcp.org/sites/default/files/201912/AMCP_Format\%204.1_1219_final.pdf

7. Garrison L, Neumann PJ, Erickson P, Marshall D, Mullins CD. Using real-world data for coverage and payment decisions: the ISPOR Real-World Data Task Force Report. Value Health. 2007;10(5):326-35.

8. Berger ML, Sox H, Willke RJ, et al. Good practices for real-world data studies of treatment and/or comparative effectiveness: recommendations from the Joint ISPOR-ISPE Special Task Force on RealWorld Evidence in Health Care Decision Making. Pharmacoepidemiol Drug Saf. 2017;26(9):1033-39.

9. Steering Committee of the Real-World Evidence Transparency Initiative Partnership. Improving transparency in non-interventional research for hypothesis testing-why, what, and how: considerations from the Real-World Evidence Transparency Initiative Partnership. Draft white paper. September 18, 2019. Accessed December 3, 2020. https://www.ispor.org/docs/ default-source/strategic-initiatives/ improving-transparency-in-non-interventional-research-for-hypothesis-testing final.pdf?sfvrsn=77fb4e97_0
10. Hampson G, Towse A, Dreitlein B, et al. Real world evidence for coverage decisions: opportunities and challenges. A report from the 2017 ICER Membership Policy Summit. March 2018. Accessed December 3, 2020. https://icer-review. org/wp-content/uploads/2018/03/ ICER-Real-World-Evidence-WhitePaper-03282018.pdf

11. Pearson S, Dreitlein B, Towse A, et al. Understanding the context, selecting the standards: a framework to guide the optimal development and use of real world evidence for coverage and formulary decisions. March 2018. Accessed December 3, 2020. https://icer-review.org/material/ rwe-white-paper-companion/

12. U.S. Food and Drug Administration. Submitting documents using real-world data and real-world evidence to FDA for drugs and biologics guidance for industry. May 2019. Accessed December 3, 2020. https://www.fda.gov/regulatory-information/search-fda-guidance-documents/ submitting-documents-using-realworld-data-and-real-world-evidence-fdadrugs-and-biologics-guidance

13. The 21st Century Cures Act. Pub L No. 114-255, 130 Stat. 1033. December 13, 2016. Accessed December 14, 2020. https:// www.congress.gov/114/plaws/publ255/ PLAW-114publ255.pdf

14. U.S. Food and Drug Administration. PDUFA reauthorization performance goals and procedures fiscal years 2018 through 2022. 2017. Accessed December 3, 2020. https://www.fda. gov/downloads/ForIndustry/UserFees/ PrescriptionDrugUserFee/UCM511438.pdf

15. The National Academies of Sciences, Engineering and Medicine. Clinical Practice Guidelines We Can Trust. The National Academies Press; 2011. Accessed December 3, 2020. http://www.nationalacademies.org/hmd/Reports/2011/ Clinical-Practice-Guidelines-We-CanTrust.aspx 
16. The National Academies of Sciences, Engineering and Medicine. Real-World Evidence Generation and Evaluation of Therapeutics: Proceedings of a Workshop. The National Academies Press; 2017. Accessed December 4, 2020. https:// www.nap.edu/catalog/24685/real-worldevidence-generation-and-evaluation-oftherapeutics-proceedings-of

17. National Institutes of Health. NIH expands program that conducts large-scale clinical trials in realworld settings. July 24, 2018. Accessed December 4, 2020. https://www.nih. gov/news-events/news-releases/ nih-expands-program-conducts-largescale-clinical-trials-real-world-settings

18. Patient-Centered Outcomes Research Institute. Pragmatic clinical studies. August 1, 2016. Accessed December 4, 2020. https://www. pcori.org/research-results/ pragmatic-clinical-studies

19. Malone DC, Brown M, Hurwitz JT, Peters L, Graff JS. Real-world evidence: useful in the real world of US payer decision making? How? When? And what studies? Value Health. 2018;21(3):326-33.

20. Hurwitz JT, Brown M, Graff JS, Peters L, Malone DC. Is real-world evidence used in P \& T monographs and therapeutic class reviews? J Manag Care Spec Pharm. 2017;23(6):613-20. doi: 10.18553/jmcp.2017.16368

21. Chambers JD. Panzer AD, Pope EF, Graff JS, Neumann PM. Little consistency in evidence cited by commercial plans for specialty drug coverage. Health Aff (Millwood). 2019;38(11):1882-86.

22. Dreyer NA, Schneeweiss S, McNeil B, et al. GRACE principles: recognizing high-quality observational studies of comparative effectiveness. Am J Manag Care. 2010;16(6):467-71.

23. Dreyer NA. Using observational studies for comparative effectiveness: finding quality with GRACE. J Comp Eff Res. 2013;2(5):413-18.
24. Dreyer NA, Velentgas P, Westrich K, et al. The GRACE Checklist for rating the quality of observational studies of comparative effectiveness: a tale of hope and caution. J Manag Care Pharm. 2014;20(3):301-08. doi: 10.18553/ jmcp.2014.20.3.301

25. Dreyer NA, Bryant A, Velentgas P. The GRACE Checklist: a validated assessment tool for high quality observational studies of comparative effectiveness. J Manag Care Pharm. 2016;22(10):1107-13. doi: 10.18553/jmcp.2016.22.10.1107

26. IMI-GetReal. RWE Navigator. Accessed December 4, 2020. https://www.imi-getreal.eu/Tools/RWE-Navigator

27. IMI-GetReal. RWE Navigator. Assuring quality and credibility of RWE. Accessed December 4, 2020. https://rwe-navigator.eu/use-real-world-evidence/ assure-quality-and-credibility-of-rwd/

28. Center for Medical Technology Policy. RWE Decoder framework, a practical tool for assessing relevance and rigor of real world evidence. A white paper from the Green Park Collaborative. February 7, 2017. Accessed December 4, 2020. http:// www.cmtpnet.org/docs/resources/ RWE_Decoder_Framework.pdf

29. Center for Medical Technology Policy. RWE Decoder: a practical tool for assessing relevance and rigor of real world evidence. Accessed December 4, 2020. http://www.cmtpnet.org/ resource-center/view/rwe-decoder/

30. Center for Medical Technology Policy. RWE Decoder framework, a practical tool for assessing relevance and rigor of real world evidence. User's guide. February 7, 2017. Accessed December 4, 2020. http:// www.cmtpnet.org/docs/resources/ RWE_Decoder_Users_Guide.pdf

31. CER Collaborative. Comparative Effectiveness Research Tool. Accessed December 4, 2020. https://www.cercollaborative.org/global/default.aspx?Redire ctURL $=\% 2$ fhome\%2fdefault.aspx
32. Berger ML, Martin BC, Husereau D, et al. Questionnaire to assess the relevance and credibility of observational studies to inform health care decision making: an ISPOR-AMCP-NPC Good Practice Task Force report. Value Health. 2014;17(2):143-56.

33. Caro JJ, Eddy DM, Kan H, et al. A modeling study questionnaire to assess study relevance and credibility to inform health care decision making: an ISPOR-AMCPNPC Good Practice Task Force report. Value Health. 2014;17(2):174-82.

34. Jansen JP, Trikalinos T, Cappelleri JC, et al. Indirect treatment comparison/ network meta-analysis study questionnaire to assess relevance and credibility to inform health care decision making: an ISPOR-AMCP-NPC Good Practice Task Force report. Value Health. 2014;17(2):157-73.

35. The Choice Institute. Real-world evidence assessments and needs guidance (REAdi) tool. Accessed December 4, 2020. https://sop.washington.edu/choice/ research/research-projects/readi/

36. Ollendorf DA, Pearson SD. An integrated evidence rating to frame comparative effectiveness assessments for decision makers. Med Care. 2010;48 (6 Suppl):S145-S52.

37. Institute for Clinical and Economic Review. ICER Evidence Rating Matrix. A user guide. Accessed December 4, 2020. http://icer-review.org/wp-content/ uploads/2013/04/Rating-Matrix-UserGuide-Exec-Summ-FINAL.pdf

38. Perfetto EM, Anyanwu C, Pickering MK, Zaghab RW, Graff JS, Eichelberger B. Got CER? Educating pharmacists for practice in the future: new tools for new challenges. J Manag Care Spec Pharm. 2016;22(6):609-16. doi: 10.18553/ jmcp.2016.22.6.609.

39. Sterne JAC, Hernan MA, Reeves BC, et al. ROBINS-I: a tool for assessing risk of bias in non-randomised studies of interventions. BMJ. 2016;355:i4919. doi: 10.1136/ bmj.i4919. 
40. National Heart, Lung and Blood Institute. Study quality assessment tools. Quality assessment tool for before-after (pre-post) studies with no control group. Accessed December 4, 2020. https:// www.nhlbi.nih.gov/health-topics/ study-quality-assessment-tools

41. Drummond MF, Jefferson TO.

Guidelines for authors and peer reviewers of economic submissions to the BMJ. The BMJ Economic Evaluation Working Party. BMJ. 1996;313(7052):275-83.

42. Sullivan SD, Mauskopf JA, Augustovski F, et al. Budget impact analysis-principles of good practice: report of the ISPOR 2012 Budget Impact Analysis Good Practice II Task Force. Value Health. 2014;7(1):5-14.
43. Critical Appraisal Skills Programme. CASP (qualitative) checklist. 2018.

Accessed December 4, 2020. https://caspuk.net/wp-content/uploads/2018/01/ CASP-Qualitative-Checklist-2018.pdf

44. Shea BJ, Reeves BC, Wells G, et al. AMSTAR 2: a critical appraisal tool for systematic reviews that include randomized or non-randomized studies of healthcare interventions, or both. BMJ. 2017;358:j4008.

45. Whiting PF, Rutjes AW, Westwood ME, et al. QUADAS-2: a revised tool for the quality assessment of diagnostic accuracy studies. Ann Intern Med. 2011;155(8):529-36.
46. Zeng X, Zhang Y, Kwong JS, et al. The methodological quality assessment tools for preclinical and clinical studies, systematic review and meta-analysis, and clinical practice guideline: a systematic review. J Evid Based Med. 2015;8(1):2-10.

47. Guyatt GH, Oxman AD, Schunemann JH, Tugwell P, Knottnerus A. GRADE guidelines: a new series of articles in the Journal of Clinical Epidemiology. J Clin Epidemiol. 2001;64(4):380-82.

48. R Studio. Shiny. Accessed December 4, 2020. https://shiny.rstudio.com/

49. Racsa PN, Meah Y, Ellis JJ, et al. Comparative effectiveness of rapid-acting insulins in adults with diabetes. J Manag Care Spec Pharm. 2017;23(3):291-98. doi: 10.18553/jmcp.2017.23.3.291

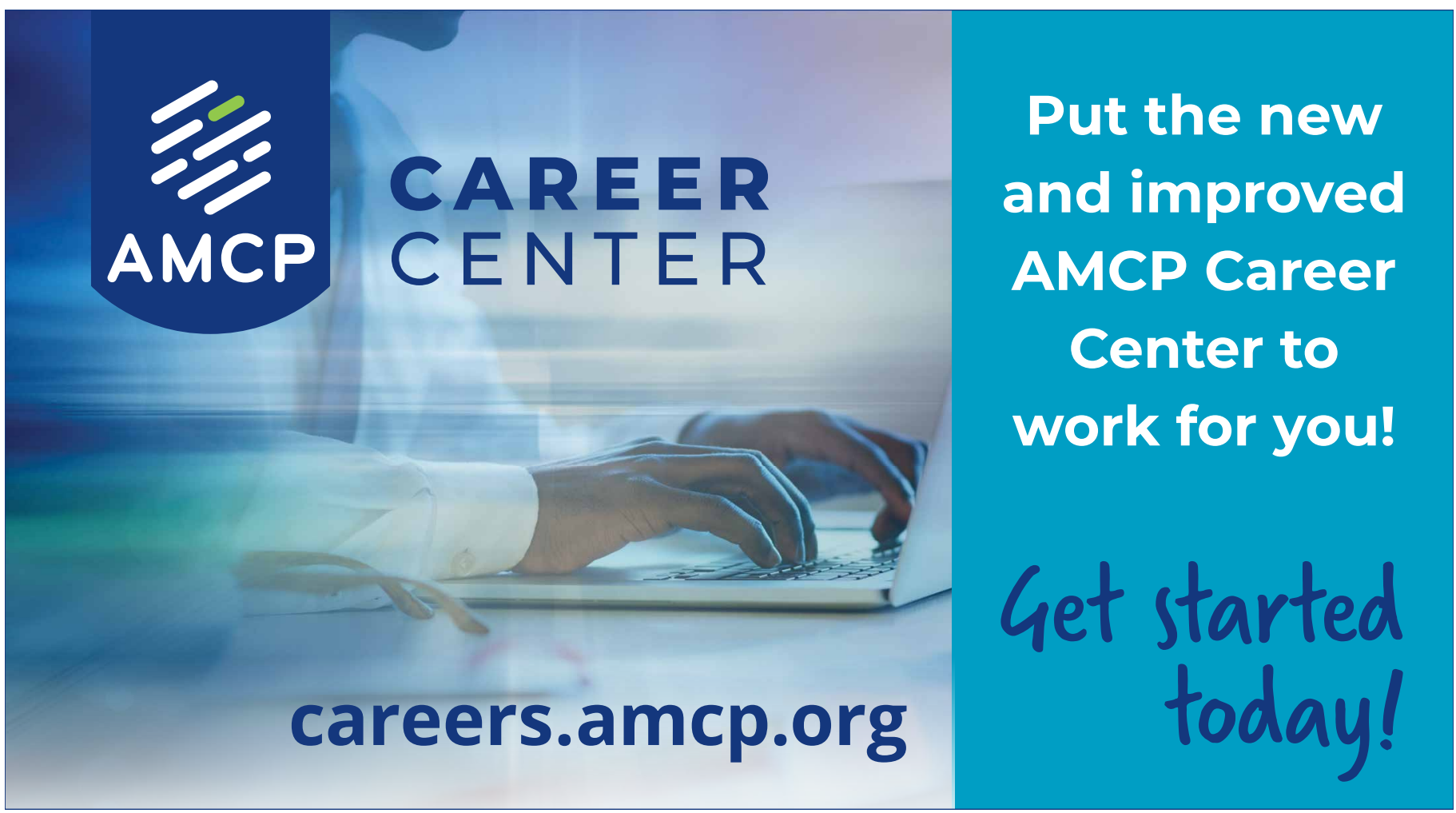

